\title{
Seasonal Variation of Diurnal Cycle of Rainfall in the Eastern Equatorial Indian Ocean
}

\author{
M.R.Ramesh Kumar ${ }^{1}$, S.M.Pednekar ${ }^{1}$, M. Katsumata ${ }^{2}$, M.K.Antony ${ }^{1}$, \\ Y. Kuroda ${ }^{2}$ and A.S.Unnikrishnan ${ }^{1}$ \\ ${ }^{1}$ Physical Oceanography Division, National Institute of Oceanography, \\ Dona Paula, Goa - 403004. India. \\ ${ }^{2}$ Institute for Observational Research for Global Change, \\ JAMSTEC, 2-15 Natsushima, Yokosuka, 237-0061, Japan
}

\section{Summary}

The diurnal cycle of rainfall over the eastern equatorial Indian Ocean is studied for the period $23^{\text {rd }}$ October 2001 to $31^{\text {st }}$ October 2003 using the hourly data from the Triton buoy positioned at $1.5^{\circ} \mathrm{S}$ and $90^{\circ} \mathrm{E}$. An analysis of the active and weak spells of the rainfall for different seasons showed that the rainfall peaked in the late evening hours in Winter, Summer and Fall seasons and in early morning hours (Spring) in 2002. The active spell of the rainfall peaked in the afternoon hours, during Winter, Spring and Summer seasons in 2003 , which agrees with the previous results of Janowiak et al (1994). An analysis of the rainfall events showed that Fall 2002 had maximum rainfall events (90) and minimum (60) were observed in Spring 2003. Further it was seen that majority of the rain events (> $60 \%$ ) were less than 3 hours duration throughout the study period. The longer duration rainfall events (i.e rain events greater than 6 hour duration) contributed significantly to Spring 2002 (20\% of the total rainfall) and Winter 2003 (21\% of the total rainfall) seasons respectively. Harmonic analysis of the hourly rainfall data for different seasons revealed that diurnal harmonic, explains more than $80 \%$ of the variance for all the seasons. Further, the diurnal harmonic has the maximum amplitude for all seasons except summer, where the semidiurnal and six hourly harmonics are significant.

Index Terms - Diurnal Variation, Rainfall, TRITON, Buoy, Eastern Equatorial Indian Ocean.

\section{Introduction}

Traditionally, the precipitation over the ocean is measured by interpolation between the rainfall over the coastal and island stations. Another way of obtaining the precipitation over the ocean is by using areal precipitation estimation derived from frequency data of ships observations. In recent years, there have been increased measurement of the precipitation from drifting and moored buoys but these observations are still few and exist only in selected regions of the global ocean.

\subsection{Earlier Work}

Ruprecht and Gray (1976) showed that the morning (07-12 LT) rainfall amounts are $2 \frac{1}{2}$ times greater than early evening amounts (19-24 LT) in the western Pacific and they attributed this to the tropical cloud clusters. Jordan (1980) using the summaries of the ship observations found that the there is a definitive early morning maximum in the precipitation frequency in the eastern tropical Atlantic throughout the year.

Sharma et al., (1991) using the morning and evening data from SSM/I sensor data onboard the Defense Meteorological Satellite Programme of U.S.A found that the morning rainfall is consistently greater than the afternoon rainfall. Further, they found that the northern hemisphere seems to have larger diurnal variation than the 
southern hemisphere. They also found that the maximum ratio between the morning to evening rainfall is 1.7 , while 1.2 is a typical value.

Kelkar et al., (1993) while analyzing the 3 hourly Outgoing Longwave Radiation (OLR) from INSAT data for the period 1987 to 1990 found that there is little variation over the oceanic region with seasons and also the minimum OLR values (maximum convection) over the oceanic region occurred in the early morning hours.

Janowiak et al., (1994) studied the diurnal cycle of oceanic tropical rainfall using satellite and in-situ data found that while the deep clouds tend to peak in the early morning hours the middle level clouds peaked in the afternoon hours.

Pathan (1996) while studying the wettest and driest hours of the day during the southwest monsoon season over the Indian region found that the maximum rainfall activity occurred in the afternoon hours over the mainland region and it occurred in night hours in the coastal regions. He attributed this difference to the differential response of the solar influence of precipitation formation mechanism over continental and coastal areas.

In a recent study, Ohsawa et al., (2001) using the hourly equivalent black body temperature $\left(T_{B B}\right)$ from the Japanese Geostationary Meteorological Satellite (GMS-5) found that the maximum convection occurs around $1400 \mathrm{hrs}$ local time in the domain, $80^{\circ} \mathrm{E}-120^{\circ} \mathrm{E}$ and $0-30^{\circ} \mathrm{N}$ and the minimum occurred in late night hours, $2100 \mathrm{hrs}$ local time. Varma et al., (2001) using the TOPEX altimeter data found that, the rain rate does not show any marked diurnal variability over the
Arabian Sea and Bay of Bengal for the period 1993-1995.

In the present study, we propose to look at the seasonal variation of diurnal cycle of rainfall using the data available from the TRITON buoy positioned at $1.5^{\circ} \mathrm{S}$ and $90^{\circ} \mathrm{E}$ in the eastern equatorial Indian Ocean for the period $23^{\text {rd }}$ October 2001 to $31^{\text {st }}$ October 2003.

\section{Data and Methodology}

The hourly rainfall data from the Triton buoy for the period $23^{\text {rd }}$ October 2001 to $31^{\text {st }}$ October 2003 have been analysed for the diurnal cycle of rainfall. Further, we have looked at the diurnal variations for different seasons, i.e. the northern hemispheric Winter (December, January and February); Spring (March, April and May); Summer (June, July and August) and Fall (September, October and November). Table 1 gives the sensor characteristics of the various surface meteorological parameters measured by the TRITON and height of the various sensors used and their range and accuracy. The data from the optical rain gauge (ORG) showed good correlation to that of the simultaneously observed capacitance rain gauge (CRG), though the ORG measured rain is larger than that of CRG's with a factor less than 2.0 (Katsumata et al., 2003). Harmonic analysis was done mainly to examine the diurnal variability of the rainfall. Four periods ( 24, 12,8 and 6 hours) were considered. The amplitudes and phases obtained for the first four harmonics and the variances are given in tables 2 , 3 and 4 . 


\section{Results and Discussion}

\subsection{Duration and Intensity}

We have examined the precipitation processes over the TRITON buoy for different seasons, further to determine the cause of the differences in the diurnal variations. We have defined a rain event using the hourly precipitation data. Continuous rain is defined as a rain event and a rain event was divided into different events if the rain intermittence was three hours or more following Kubota et al., (2005). Figure 1 depicts the time series of hourly precipitation from 0000 LT (local time) $29^{\text {th }}$ June to 2300 LT $30^{\text {th }}$ June 2002. There are four rain events observed using the above definition. An analysis of the rainfall events showed that fall 2002 had maximum rainfall events (90) and the spring 2003 had minimum (60). Further it was seen that majority of the rain events (> 60\%) were of 1-3 hour duration throughout the study period. The longer duration rainfall events (i.e rain events greater than 6 hour duration) contributed significantly to Spring 2002 (20\% of the total rainfall) and Winter $2003(21 \%$ of the total rainfall) seasons respectively as compared to other seasons.

\subsection{Active and weak spells}

In order to gain more information about the diurnal cycle during different seasons, we further classified them as active and weak spells within each season, depending upon the daily rainfall data. We classified a day as active if the rainfall for a particular day was more than $m+\sigma$ and as weak if the rainfall was less than $m-\sigma$, where $m$ and $\sigma$ stands for the average and standard deviation of daily rainfall for that season. Further we made composites of active and weak days for each season for looking into diurnal cycle of rainfall. An analysis showed of the seasonal diurnal cycle of the active and weak spells for 2002-2003 showed the following features. a) The rainfall increased from early morning hours to a maximum in the evening hours during winter 2002 during active spells (figure 2). The rainfall during weak spells did not show much trend. b) The diurnal cycle of rainfall showed a decreasing trend from early morning hours to night during the active spells period of Spring 2002 (figure 3). The diurnal cycle of rainfall during the weak spells did not show any trend. c) During the summer of 2002, the diurnal cycle of rainfall during the active phase was found to increase from early morning hours to night with a minimum during the evening hours (17-18 hrs LT) (figure 4). d) During the fall 2002, the diurnal cycle of rainfall shows that the rainfall during the weak spells is more than active spells during the early morning hours (00-01 hrs LT). The diurnal cycle of rainfall for active spells, further shows an increase from early morning hours to late evening hours and then decreases further during late night hours (figure 5). e) During winter 2003, the diurnal cycle shows a steady increase from early morning hours and reaches a maximum during afternoon hours and then decreases to evening and late night hours (figure 6). f) The diurnal cycle of spring 2003, showed that rainfall maxima occurred during noon hours (1100 hrs LT) and minimum during night hours (21-22 hrs LT) and early morning hours (01-02 hrs LT). The diurnal cycle of rainfall during the weak spell showed a significant with maxima in the early morning hours (0400 hrs LT) (figure 7). g) The summer of 2003 showed a significant diurnal cycle with a rainfall maxima (figure 8 ) during the late morning hours (0800-1100 hrs LT) and a minima during the late night and early morning hours (2300-0200 hrs LT). 
The release of convective instability through organized low level convergence and this can be associated with one of the following systems, such as synoptic scale systems, meso-scale systems and interaction between mesp-scale and large scale systems. In the eastern equatorial Indian Ocean, precipitation dominates the evaporation throughout the year as can be seen from the annual cycle of fresh water flux values (E-P) for the study area using the Hamburg Ocean Atmosphere Parameters and fluxes from satellite data (Grassl et al., 2000). Thus region is quite conducive for large scale low level moisture convergence.

Further, there is large diurnal variability in the precipitation over the eastern equatorial Indian Ocean with the ratio maximum to minimum rainfall varying from 2.2 times in winter of 2002 to almost 9 times in spring of 2002. This is in sharp contrast to the earlier results of Varma et al., who did not find any diurnal variation in rainfall over the Arabian Sea and Bay of Bengal and Sharma et al., (1991) who also found only slight increase in the ratio of the morning hours to the evening rainfall, which varied from 1.2 times to 1.7 times.

\section{Conclusions}

Unlike most of the previous results, the eastern equatorial Indian Ocean exhibited significant diurnal variation in rainfall during the study period. The rainfall amounts were maximum during the 18-21 hrs in Winter and Summer seasons of 2002. In Spring 2002, the maximum rainfall occurred during the early morning hours (00-03) hrs. In fall 2002, the maximum occurred in late night hours (21-24) hrs. In 2003, during all the seasons, the maximum occurred in the hours (12-15) hrs local time, which agrees with earlier study of Janowiak et al., (1994). Further, the ratio of maximum to minimum also varied significantly from 2.2 times in winter of 2002 to 9 times in spring of 2002. The reason for the significant shift in the maximum rainfall for different seasons of the study could be a result of variety of mechanisms mentioned by the previous studies, as it is very difficult to pinpoint a particular causative mechanism is at work for different seasons.

\section{Acknowledgements}

This work forms a part of the NIO - JAMSTEC collaborative programme which is funded by the Japan Agency for Marine Earth Science and Technology center (JAMSTEC). M.R.Ramesh Kumar would like to thank the Department of Science and Technology, New Delhi, India for providing the travel funds and to the JAMSTEC, Japan for providing the local hospitality. The authors would like to thank Dr. John Janowiak, CPC, NOAA/NWS/NCEP, U.S.A and Dr. Peter Bauer, Scientist, ECMWF, Reading, U.K. for their useful suggestions in improving the manuscript.

\section{References}

Grassl, H., Jost, V., Ramesh Kumar, M.R., Schulz, J., Bauer, P., and Schluessel, P., The Hamburg Ocean Atmosphere Parameters and Fluxes from Satellite Data (HOAPS), 2000: A climatological Atlas of satellite derived Air-Sea Interaction parameters over the Oceans, Report. No. 312, Maximum Planck Institute for Meteorology, Hamburg, Germany.

Hendon, H.H., and K. Woodberry, 1993: Diurnal cycle of tropical convection, J. Geophys. Res., 98, 16623-16637.

G.J.Huffman, R.F. Adler, P.A. Arkin, A. Chang, R. Ferraro, A. Gruber, J. Janowiak, A. McNab, B. 
Rudolf and U. Schneider, 1997: The Global Precipitation Climatology Project (GPCP) Combined Precipitation Dataset, Bull. Amer. Meteorol. Soc., 78, 5- 20.

Janowiak, J.E., Arkin, P.A., and Morrissey, M., 1994: An examination of the diurnal cycle in oceanic tropical rainfall using satellite and in-situ data, Mon. Wea. Rev., 122, 2296-2311.

Jordan, C.L., 1980: Diurnal Variation of Precipitation in the eastern tropical Atlantic, Mon.

Wea. Rev., 108, 1065-1068.

Katsumata, M., Ando K., and Kuroda, Y., 2003: Long-term simultaneous observation of the optical rain gauge and the capacitance rain gauge on the TRITON buoy. Prep. Meeting of Oceanographic Soc. Japan in Fall 2004, 209 (in Japanese). Kelkar, R.R., Rao, A.V.R.K., and Sant Prasad, 1993: Diurnal Variation of outgoing longwave radiation derived from INSAT-1B data, 44,45- 52. Kubota, H., Shirooka, R., Ushiyama, T., Chuda, T., Iwasaki, S., and Takeuchi, K., 2005: Seasonal variations of Precipitation Properties associated with monsoon over Palau in the western Pacific, Journal of Hydrometeorology (in Press).

Ohsawa, T., Ueda, H., Hayashi, T., Watanabe, A., and Matsumoto, J., 2001: Diurnal Variations of convective activity and rainfall in tropical Asia, J. Meteorol. Soc. Japan, 79, 333- 352.

Pathan, J.M., 1994: Diurnal Variation of southwest Monsoon Rainfall at Indian Stations, Adv. Atmos. Sci., 11, 111-120.

Randall, D.A., Harshvardhan, and Dazlich, D.A., 1991: Diurnal Variability of the hydrologic cycle in a general circulation model. J. Atmos. Sci., 48, 40-62.

Ruprecht, E., and Gray, W.M., 1976: Analysis of Satellite observed tropical Cloud Clusters Part II. Thermal, moisture and Precipitation Tellus, 28 , 414-426.

Sharma, A.K., Chang, A.T.C. and Wilheit, T.T.,1991: Estimation of diurnal cycle of oceanic precipitation from SSM/I data. Mon. Wea. Rev., 119, 2168-2175.

Varma, A.K., Gairola, R.M., Pandey, P.C., and Sigh, K.P., 2001: Use of TOPEX altimeter for the study of diurnal and spatial distribution of southwest monsoon rainfall over the Bay of Bengal and the Arabian Sea, Rem. Sens. Environ., 77, 112-121. 
Table 1: Sensor characteristics of surface meteorological parameters of the TRITON buoy

\begin{tabular}{|l|l|l|l|l|}
\hline Sensor & Range & Resolution & Accuracy & $\begin{array}{l}\text { Height } \\
\text { Sensor }\end{array}$ \\
\hline Wind Speed & 0 to $60 \mathrm{~m} / \mathrm{s}$ & $0.1 \mathrm{~m} / \mathrm{s}$ & $0.3 \mathrm{~m} / \mathrm{s}$ & $\begin{array}{l}3.5 \text { above } \\
\text { sea surface }\end{array}$ \\
\hline $\begin{array}{l}\text { Wind } \\
\text { Direction }\end{array}$ & 0 to 360 & 1 & 2 & $\begin{array}{l}3.5 \text { above } \\
\text { sea surface }\end{array}$ \\
\hline $\begin{array}{l}\text { Shortwave } \\
\text { radiation }\end{array}$ & 0 to 1400 & $0.1 \mathrm{~W} / \mathrm{m}^{2}$ & $0.5 \mathrm{~W} / \mathrm{m}^{2}$ & $\begin{array}{l}3.0 \text { m above } \\
\text { sea surface }\end{array}$ \\
\hline $\begin{array}{l}\text { Relatve } \\
\text { Humidity }\end{array}$ & 0 to $100 \%$ & $0.1 \%$ & $2 \%$ & $\begin{array}{l}2.2 \text { above } \\
\text { sea surface }\end{array}$ \\
\hline $\begin{array}{l}\text { Air } \\
\text { Temperature }\end{array}$ & -20 to $50{ }^{\circ} \mathrm{C}$ & $0.01{ }^{\circ} \mathrm{C}$ & $0.1 \mathrm{C}$ & $\begin{array}{l}2.2 \text { m above } \\
\text { sea surface }\end{array}$ \\
\hline $\begin{array}{l}\text { Precipitation } \\
\text { to } 500\end{array}$ & $\begin{array}{l}0.01 \mathrm{~mm} \\
\mathrm{~mm} / \mathrm{hr}\end{array}$ & $\begin{array}{l}3.0 \text { m above } \\
\text { sea surface }\end{array}$ \\
\hline Air Pressure & $\mathrm{hPa}-1100$ & 0.0038 & 0.01 & $\begin{array}{l}2.0 \text { m above } \\
\text { sea surface }\end{array}$ \\
\hline
\end{tabular}

Table 2: Amplitude (cms) of the first four Harmonics for different seasons.

\begin{tabular}{lllll}
\hline Harmonic & WIN & SPR & SUM & FAL \\
\hline First & 0.10 & 0.12 & 0.03 & 0.23 \\
Second & 0.03 & 0.10 & 0.14 & 0.05 \\
Third & 0.04 & 0.02 & 0.08 & 0.15 \\
Fourth & 0.01 & 0.06 & 0.12 & 0.08 \\
\hline
\end{tabular}

Table 3: Phase (hrs) of the first four Harmonics for different seasons.

\begin{tabular}{lllll}
\hline Harmonic & WIN & SPR & SUM & FAL \\
\hline First & 14.6 & 4.9 & 11.3 & 20.5 \\
Second & 9.9 & 11.4 & 9.1 & 9.6 \\
Third & 2.3 & 4.6 & 3.3 & 0.4 \\
Fourth & 4.9 & 5.5 & 2.1 & 3.9 \\
\hline
\end{tabular}


Table 4: Sum of the variances (in \%) of the first four Harmonics for different seasons.

\begin{tabular}{lcccc}
\hline Harmonic & WIN & SPR & SUM & FAL \\
\hline I & 88 & 88 & 83 & 80 \\
I+II & 88 & 90 & 86 & 81 \\
I+II+III & 88 & 91 & 88 & 84 \\
I+II+III+IV & 88 & 92 & 91 & 85 \\
\hline
\end{tabular}



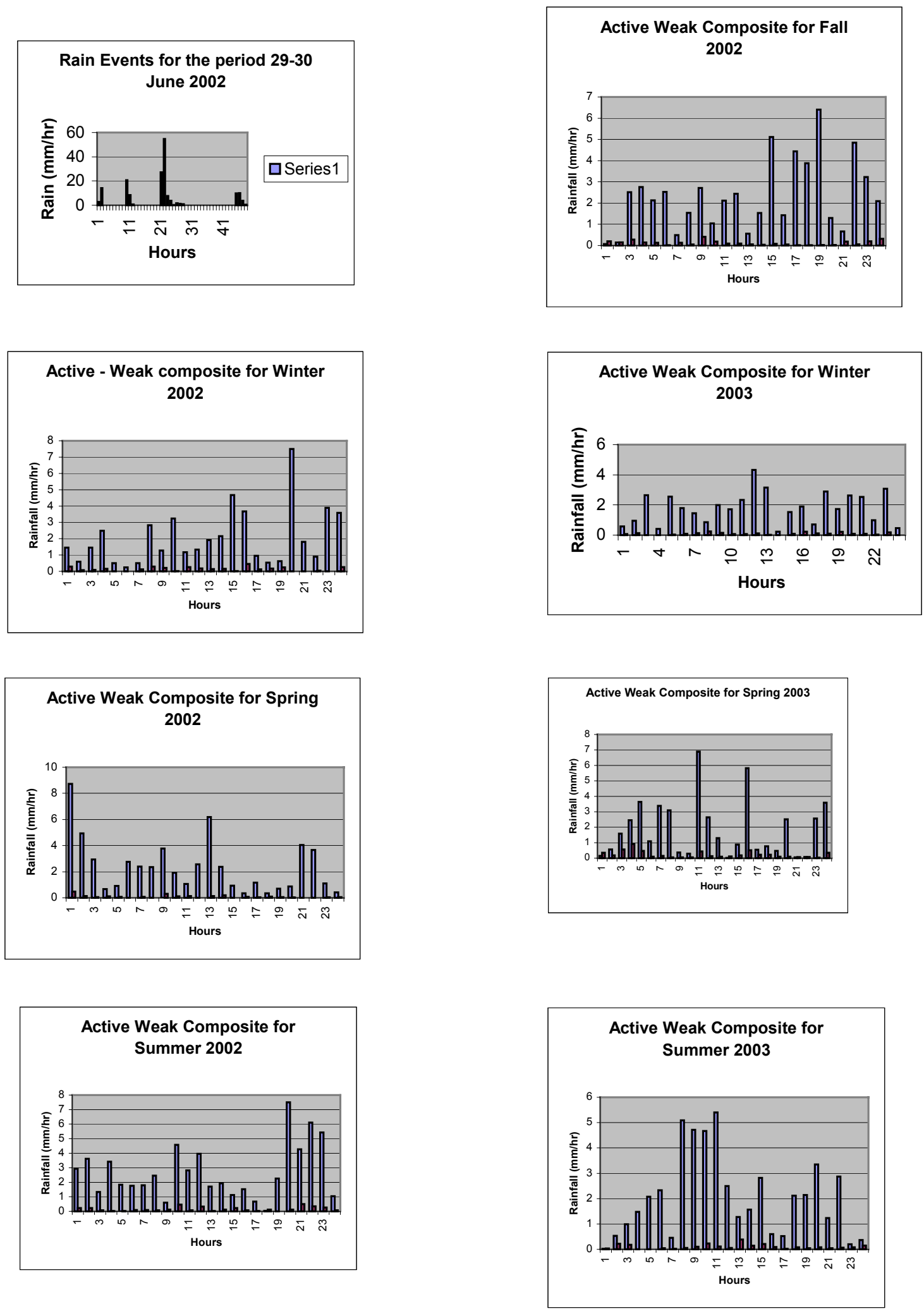
Figure 5: Diurnal Variation of Rainfall for different seasons, Winter (A), Spring (B), Summer (C) and Fall (D). The small circle points give the observed values along with the fits for the diurnal harmonic (solid) and sum of the diurnal and semidiurnal harmonics (dashed) are plotted.
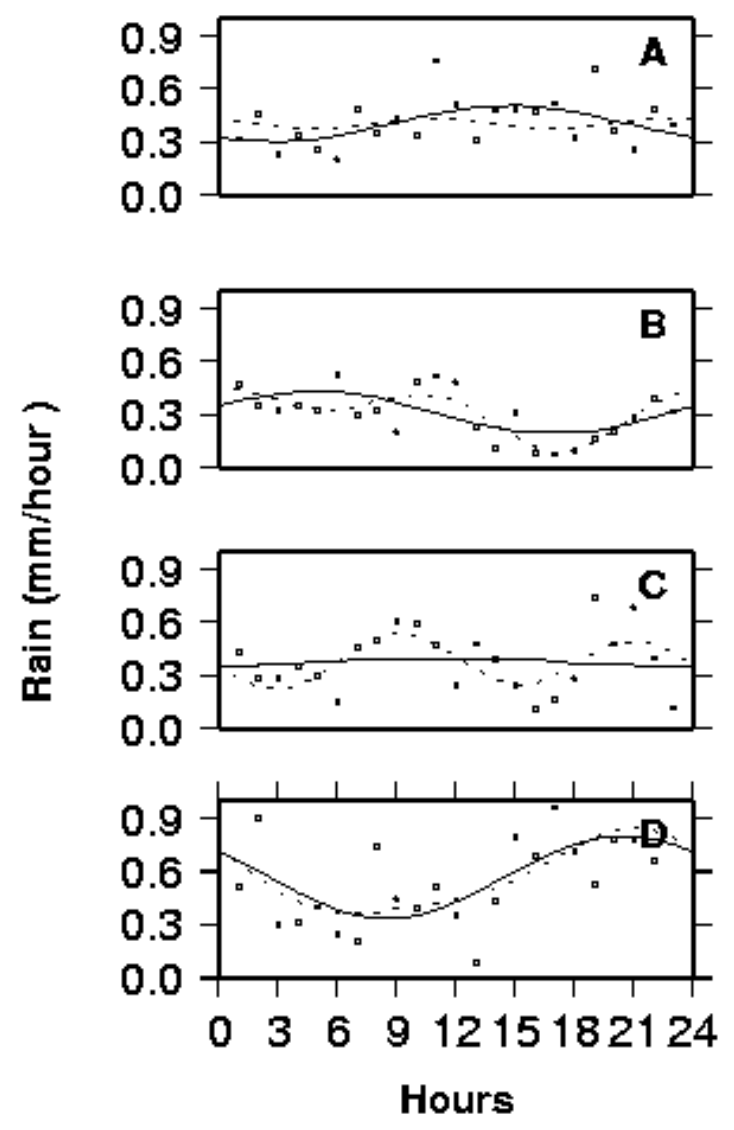